\title{
Controversies Surrounding Classification of Personality Disorder
}

\author{
Youl-Ri Kim ${ }^{1,2} \bowtie$ \\ Peter Tyrer ${ }^{2}$ \\ ${ }^{1}$ Department of Neuropsychiatry, \\ Inje University College of Medicine, \\ Seoul Paik Hospital, Seoul, Korea \\ ${ }^{2}$ Centre for Mental Health, \\ Division of Experimental Medicine, \\ Imperial College, London, UK
}

\author{
$\triangle$ Correspondence \\ Youl-Ri Kim, MD, PhD \\ Department of Neuropsychiatry, \\ Inje University College of Medicine, \\ Seoul Paik Hospital, \\ 85 Jeo-dong 2-ga, Jung-gu, \\ Seoul 100-032, Korea \\ Tel +82-2-2270-0063 \\ Fax +82-2-2270-0344 \\ E-mailyyoulri.kim@paik.ac.kr
}

(c) This is an Open Access article distributed under the terms of the Creative Commons Attribution Non-Commercial License (http://creativecommons.org/licenses/by-nc/3.0) which permits unrestricted non-commercial use, distribution, and reproduction in any medium, provided the original work is properly cited.
Nowadays, it is apparent that personality disorder is a common condition. Some of the concepts of personality disorder that are currently in use are flawed and need to be revised. The aim of this article is to discuss the controversy created by the uncertainties in the current classification system and to suggest ways forward. In particular, the clinician needs to be aware of the importance of assessing personality abnormality in terms of a severity dimension, and of the ways in which such an abnormality can impact on treatments for other conditions. These changes in the notion of personality disorder are needed as, for the first time, a good evidence base is being established for potential treatments and these will be maximized if we have a classification fit for therapeutic purpose.

Psychiatry Investig 2010;7:1-8

Key Words Personality disorder, Classification, Severity, Treatment.

Received: October 22, 2009 Revised: December 24, 2009 Accepted: January 10, 2010 Available online: February 8, 2010

\section{Introduction}

Personality disorders are quite common, as epidemiological studies suggest that their prevalence varies from $5-13 \%$ of the population in the community, ${ }^{1}$ but rises to around $30 \%$ of primary care attendees ${ }^{2}$ to $40-50 \%$ of those in secondary care, ${ }^{3}$ and between $70-90 \%$ of those in tertiary psychiatric services and prisons. ${ }^{4,5}$ In the last 50 years, there has been increasing recognition that personality disorder can be described and rated reliably, despite the many imperfections in its classification. Nowadays, there is general agreement among personality disorder researchers that a fundamental change is needed in its classification. The aim of this article is to introduce advanced notions of personality disorder. For this purpose, we describe the controversy created by the uncertainties in the classification of personality disorder.

\section{Current Classification of Personality Disorder}

Most Korean psychiatric professionals are familiar with the Diagnostic and Statistical Manual of Mental Disorders (DSM) classification system. ${ }^{6}$ Although the International Classification of Disease (ICD) ${ }^{7}$ is the world classification, and therefore takes precedence over other classifications, most of the changes made in the classification of personality disorder in the last 30 years have been a direct consequence of the introduction of the third revision of DSM (DSM-III) in $1980 .{ }^{8}$ Although the individual diagnostic criteria of personality disorder are very similar in ICD-10 and DSM-IV, there is one fundamental difference between them, which is that the DSM recorded personality disorder as a separate axis of classification (Axis II) from mental state disorders (Axis I). This was quite sound at the time, because personality was considered to be in a completely different domain from that of mental state disorders. The reasons for making the separation are summarized on Table 1. One of the other reasons for separating personality and mental disorders into separate axes is that the problem of comorbidity becomes much less of a diagnostic problem once this separation is made. Subsequent- 
Table 1. Differences between Axis I disorders and personality disorders

\begin{tabular}{ll}
\hline Axis I disorders & Personality disorders \\
\hline Temporary (usually) & Permanent (or at least long-standing) \\
Reactive & Generative \\
Dominated more by symptoms than behavior & Dominated mainly by behavior and relationships with others \\
Diagnosed mainly on present state & Diagnosed on basis of long-term function \\
May develop into other Axis I disorders & Tends to remain stable \\
\hline
\end{tabular}

Table 2. General diagnostic criteria for a personality disorder (derived from DSM-IV and ICD-10 guideline)

A An enduring pattern of inner experience that deviated markedly from the expectations of the individual's culture.

This pattern is manifested in two (or more) of the following areas:

i) Cognition, i.e., ways of perceiving and interpersonal self, other people and events

ii) Affectivity, i.e., the range, intensity, lability, and appropriateness of emotional response

iii) Interpersonal functioning

iv) Impulsive control.

B This pattern is inflexible and pervasive across a broad band of personal and social situations.

C The pattern leads to clinically significant distress and/or impairment in social, occupational, or other important areas of functioning.

D The pattern is stable and of long duration and its onset can be traced at least to adolescent or early childhood.

E The enduring pattern is not better accounted for as a manifestational consequence of another mental disorder.

DSM-IV $^{6}$ : the Diagnostic and Statistical Manual of Mental Disorders 4th edition, ICD-107 : the International Classification of Disease, 10th Version

ly, it may be appropriate to define a group of 'co-axial syndromes' in which certain Axis I disorders are found in association with Axis II disorders. ${ }^{9}$

The current guidelines for the diagnosis of the personality disorder group category in ICD-10 and DSM-IV are shown in Table 2. In both classifications, the first stage is to decide whether an individual has personality disorder before deciding on his/her classification type. Both classifications are similar in that they have no mechanism for rating the severity of the personality disturbance, which makes it difficult for the clinician to plan and provide treatment.

\section{Comorbidity of Personality Disorder with Axis I Disorders}

It is becoming increasingly recognized that Axis I disorders do not encompass all syndromes with poor prognoses. The co-occurrence of Axis I disorders and Axis II personality disorder has consistently shown the worst prognosis, often approximating to the sum of the Axis-associated risks and sometimes reaching several times the risk of the Axis I disorder alone. ${ }^{10}$ Social impairment is common in patients with mental illness; however, social dysfunction that persists over time is more likely to be a consequence of personality disorder than mental illness. If clinicians were able to diagnose comorbid personality problems comprehensively, they would be able to feel confident about planning their care and predicting the outcomes of the patients with the Axis I disorders they frequently treat.

The studies undertaken to date, although having similar limitations to epidemiological researches, broadly support the conclusion that the outcome in Axis I disorders is poorer when a personality pathology is present. ${ }^{11}$ When adolescent personality disorders coexist with Axis I disorders, the long-term prognosis tends to be much worse than that for Axis I disorders only. ${ }^{10}$ Other research which longitudinally examined the interaction of personality pathology and major mental illness also supports the poor outcomes in co-morbid personality disordered patients. ${ }^{12}$ Cross-sectional data has also suggested that personality disorder is associated with greater dysfunction in those with mental illnesses. ${ }^{13}$ Researchers argued that personality disorders should be recognized as risk factors in their own right for long-term dysfunction and distress. ${ }^{10}$ Previous studies do not make it clear how personality disorder acts as a diathesis under these conditions. This negative effect of personality dysfunction on the outcome of Axis I disorders may be potentially multifaceted, including such aspects as the lack of treatment directed at the personality pathology or the clinician's perception of these patients as a difficult group to manage. ${ }^{14}$

\section{Controversies Surrounding the Classification of Personality Disorder}

\section{Controversy I. Is personality disorder best classified as categories or dimensions?}

The DSM classification has been used to define the behavioral elements of personality disorder since DSM-III. ${ }^{8}$ Although this categorical approach is appropriate for depression 
and schizophrenia, it is not suitable for personality disorder, due to its heterogeneous description. ${ }^{15}$ When all of the operational criteria of personality disorder were assessed carefully, it was found that their distribution was quite unlike that of DSM. ${ }^{16}$ The other major problem with classifying personality disorder into categories is that most people with this condition qualify for more than one category. In order for the classification systems themselves to be well integrated and coordinated with basic science research on general personality structure, it is necessary for them to be closely coordinated with the classification of personality disorder in people with normal personality traits. ${ }^{17}$ The alternative of a dimensional system views personality as a continuum and, in this system, personality disorder shows the same pattern of distribution as a normal personality. The dimensional system existed before the introduction of DSM-III and has since been revised and reformulated many times, ${ }^{18-21}$ but is only now beginning to show realistic potential for widespread adoption in clinical psychiatry. Thus, it is realistic to examine both the dimensional and categorical approaches to personality disorders in the current situation, ${ }^{17,20,22}$ and the grading of severity is valuable in practice and also helps to accommodate the large number of patients who are diagnosed with unspecified personality disorders.

\section{Controversy 2. Which personality variables should be assessed in the assessment of personality disorder?}

There continues to be some debate as to which personality variables should be assessed to make a diagnosis of personality disorder in the normal/abnormal personality continuum. . $^{19,21,23-26}$ It would seem to be appropriate in this approach to choose those personality variables more likely to be personal and concerned with functioning, in order to assist in understanding the patient's disabilities and obtain strong clues about them. The difficulties encountered in the diagnosis and study of personality disorder include inconsistencies in assessment across both instruments and raters. The cross-instrument reliability between self-report and interview assessments in personality disorders is remarkably poor (kappa $=0.27)^{27}$ and this poor agreement may explain why the research results cannot be replicated, despite the fact that the groups carry the same diagnostic label. The instrument of choice in assessing personality disorder is the structured interview schedules, mainly because their reliability and differing types of validity are superior to those of questionnaires. There are more than 10 personality interview schedules currently in use and more are being developed. ${ }^{22,28-30}$ The earliest is the Personality Assessment Schedule (PAS) developed in 1976 and since revised. ${ }^{31}$ PAS identifies 24 dimensions of personality traits/characteristics that were commonly found in personality disorder and determines to what extent they can be grouped together in terms of both their nature and severity. The value of written records describing the patient's attitudes and habitual behavior has rarely been fully appreciated. Additional information derived from the records is almost certainly critical, and this method of assessment is more helpful than other methodologies. ${ }^{32} \mathrm{~A}$ document-derived version drawn from the PAS (the Schedule for Personality Assessment from Notes and Documents: SPAN-DOC $)^{15}$ has been developed with a similar underlying structure. The personality traits investigated in SPAN-DOC are classified into 26 dimensions and rated on a nine-point scale, which produces the following categories: sociopathic, explosive, passive-dependent, anankastic, schizoind, sensitiveaggressive, histrionic, asthenic, anxious, paranoid, hypochondriacal, dysthymic, and avoidant. In Table 3, there is a comparison between the 18 scale items of the Dimensional As-

Table 3. Comparison between the 26 traits of SPAN-DOC and the 18 factors of DAPP-BQ

\begin{tabular}{ll}
\hline SPAN-DOC dimension & DAPP-BQ dimension \\
\hline Moodiness/Emotional lability & Affective lability \\
Anxiousness & Anxiousness \\
Anger/irritability & Rejection \\
Vulnerability & (No equivalent) \\
Resourcelessness & Passive oppositionality \\
Suspiciousness/Mistrust & Suspiciousness \\
Hypersensitivity & (No equivalent) \\
Aggression & Interpersonal disesteem \\
Worthlessness & (No equivalent) \\
Suicidality & Self-harm \\
Eccentricity & Cognitive distortion \\
Emotional dependence/neediness & Narcissism \\
Passive dependence/indecisiveness & Insecure attachment \\
Anhedonia & (No equivalent) \\
Entitlement & Narcissism \\
Exhibitionism & (No equivalent) \\
Introspection/introversion & Restrictive expression \\
Shyness & Diffidence and social \\
Aloofness/Coldness/Detachment & Intimacy problem \\
Sensation/Novelty seeking & Stimulus seeking \\
Impulsivity & (No equivalent) \\
Hyperperfectionism & Compulsivity \\
Callousness & Callousness \\
Irresponsibility & Conduct problem \\
Inflexibility & Compulsivity \\
Hypochondriasis & (No equivalent) \\
\hline One DAPP dimse & \\
\hline &
\end{tabular}

One DAPP dimension (identity problem) has no equivalent in SPAN-DOC. SPAN-DOC ${ }^{15}$ : the Schedule for Personality Assessment from Notes and Documents, DAPP-BQ ${ }^{33}$ : the Dimensional Assessment of Personality Pathology-Basic Questionnaire 
sessment of the Personality Pathology-Basic Questionnaire (DAPP-BQ) ${ }^{33}$ derived from the 282 self-report items and the 26 traits rated by SPAN-DOC. Despite the fact that they were derived from different sources, there is a high degree of commonality between the two systems that supports the notion that they are measuring the same basic constructs.

\section{Controversy 3. Is diagnosis of personality disorder stable?}

Though the definitive feature of personality disorder in the DSM classification is that it is 'pervasive', it now looks as through this definition is incorrect. There is abundant evidence that personality traits are unstable, ${ }^{34-38}$ and there is also evidence for greater stability of social dysfunction in long-term studies. ${ }^{36,39}$ Whereas in the past this lack of stability was regarded as a contaminating effect of mental state or a poor assessing instrument, the growing evidence that it seems to be universal has prompted a change of view. Thus, only personality function, rather than disorder, can be accurately assessed at any point in time. In a longitudinal study, all four personality disorders (borderline, schizotypal, avoidant, and obsessive-compulsive) showed similar improvements after 2 years, with the highest rate of remission being $61 \%$ in schizotypal personality disorder and the lowest $50 \%$ in avoidant personality disorder. ${ }^{37,40}$ However, in studies using a self-rated instrument for dependent personality, dependent personality features showed high stability. ${ }^{41}$ There is also evidence from epidemiological studies that cluster A pathology persists into older age. ${ }^{42}$

Fortunately, a consistent finding from studies on the treatment of personality disorder is that, both in the short and longer term, those patients who present themselves for the treatment of their personality disorders show a steady improvement. ${ }^{34,36,37,43-45}$ This improvement is generally greater for those with borderline personality disorder than for those with other disorders.

\section{Controversy 4. Can personality disorder be graded by severity?}

It has become increasingly clear that some form of severity assessment is necessary to decide on the priorities to use for the management of personality disorder. The notion of severe personality disorder is central to much of the work in the area of forensic psychiatry. What is clear from empirical research studies is that those with more severe personality disorder do not have stronger manifestations of one single disorder as often postulated, ${ }^{46}$ but instead their personality disturbance extends across all domains of personality. ${ }^{46-48}$ Although severity is not normally taken into account when classifying mental illness, it is important in personality disorders, as normal personality and personality disorder are both on the same continuum. Unfortunately, there is no measure of severity for personality disorder in the DSM or ICD classification, and the absence of these measures is of significant concern. Indeed, treatment is justified when it is likely to ameliorate distressing or disabling syndromes, even when the patients fail to meet the full diagnostic criteria of psychiatric disorders and, consequently, the measure of severity is highly relevant to the planning and provision of treatment. A reliable way of assessing personality disorder is to use 3 levels of severity (Table 4). By using this measure of severity, it is possible to use the cluster system to get a measure of severity and this measure is also relevant in assessing those with the most severe personality disorders in forensic psychiatry.

\section{Research on Personality Disorder in Korea}

Personality disorder is now being accepted as an important condition in mainstream psychiatry throughout the world. Recently, this disorder has become more prominent in the international research literature. ${ }^{15}$ In Korea, however, there have been few studies on personality disorder.

Table 4. Assessment of severity in personality disorder

\begin{tabular}{|c|c|}
\hline Level of severity & Definition \\
\hline $\begin{array}{l}\text { 1-Personality } \\
\text { difficult }\end{array}$ & $\begin{array}{l}\text { An enduring pattern of perceiving, relating to and thinking about the environment and oneself that is inflexible, } \\
\text { deviates from cultural expectations and is exhibited across social and personal contexts. People with person- } \\
\text { ality-related difficulties do not pose a risk to self or others and social dysfunction is minimal. }\end{array}$ \\
\hline $\begin{array}{l}\text { 2-Simple personality } \\
\text { disorder }\end{array}$ & $\begin{array}{l}\text { An enduring pattern of perceiving, relating to and thinking about the environment and oneself that is inflexible, } \\
\text { deviates markedly from cultural expectations and is exhibited in a wide range of social and personal contexts. } \\
\text { Problems should be apparent in at least two of the domains of cognition, affectivity, control over impulses, } \\
\text { gratification of needs, and handling interpersonal relationships and be associated with either impaired social } \\
\text { functioning and/or evidence of risk to self and/or others. }\end{array}$ \\
\hline $\begin{array}{l}\text { 3-Severe personality } \\
\text { disorder }\end{array}$ & $\begin{array}{l}\text { An enduring pattern of perceiving, relating to and thinking about the environment and oneself that is inflexible, } \\
\text { deviates markedly from cultural expectations and is exhibited in a wide range of social and personal contexts. } \\
\text { To qualify as severe, personality-related problems should be complex, apparent across a wide range of do- } \\
\text { mains including cognition, affectivity, control over impulses, gratification of needs, and handling interpersonal } \\
\text { relationships, and be associated with either grossly impaired social functioning and/or clear evidence of risk } \\
\text { of severe harm to self and/or others. }\end{array}$ \\
\hline
\end{tabular}


We searched for articles on personality disorder in the official journals of the national psychiatric associations covering general psychiatry in the Republic of Korea, United Kingdom, and United States of America, for the quantitative analysis of research on this subject. The selected journals are the Psychiatry Investigation (PI) for the Korean Neuropsychiatric Association, the British Journal of Psychiatry (BJP) for the Royal College of Psychiatrists, and the American Journal of Psychiatry (AJP) for the American Psychiatric Association. In addition, we searched for articles on personality disorder originating from Korea published in internationally cited (SCI) psychiatric journals. Articles were searched for using the ISI Web of Science electronic databases and the official websites for each journal in the past 3 years (January 2007 to December 2009), and the search keyword term was PERSONALITY DISORDER. Two of the journals (BJP, AJP) were monthly publications, while the other journal (PI) was published biannually until 2008 and quarterly from 2009. The results

Table 5. Treatment trials in people with personality disorder*

\begin{tabular}{|c|c|c|}
\hline Type of treatment & Results & Recommendation \\
\hline $\begin{array}{l}\text { Psychodynamic treatment linked to } \\
\text { day hospital and mentalisation- } \\
\text { based treatment (borderline } \\
\text { personality disorder) }\end{array}$ & $\begin{array}{l}\text { Small randomized controlled trial with } \\
\text { excellent results for symptoms, self-harm, } \\
\text { hospitalization and costs of care }{ }^{54-57}\end{array}$ & $\begin{array}{l}\text { Needs replication, but results at this stage } \\
\text { sufficient to suggest that day hospitals could } \\
\text { well refocus on this group using principally } \\
\text { this approach }\end{array}$ \\
\hline $\begin{array}{l}\text { Dialectical behavior therapy (DBT) } \\
\text { (borderline personality disorder, } \\
\text { some exclusively with women) }\end{array}$ & $\begin{array}{l}\text { Series of small randomized trials showing } \\
\text { definite advantages of DBT over treatment as } \\
\text { usual for self-harming behavior, with other } \\
\text { symptoms equivocal and some loss of effect }\end{array}$ & $\begin{array}{l}\text { Now an established treatment although the } \\
\text { evidence base is still somewhat slim, } \\
\text { particularly for men }\end{array}$ \\
\hline
\end{tabular}

Cognitive Behavioral Therapy (CBT) and problem solving therapy (treatment in self-harm population, in which $42 \%$ had personality disorders and $91 \%$ had personality disturbance of some type)

Cognitive analytical therapy (borderline personality disorder) Therapeutic communities

Transference-focused psychotherapy (borderline personality disorder)

Nidotherapy (treatment suitable for Type R personality disorders)

Haloperidol and other typical antipsychotics in low dosage (mainly borderline personality disorders)

Selective serotonin reuptake inhibitors (SSRIs)

Other drugs, including mood stabilizers, atypical antipsychotics, omega-3 fatty acid and monoamine oxidase inhibitors symptoms equivocal and some loss of effect over time s8,59 $^{58}$

One small trial suggesting efficacy ${ }^{60}$; second showing less effect but cost-effective in brief form in large trial $(n=480) .{ }^{61,62}$ Problemsolving psychotherapy effective in preventing self-harm recurrence ${ }^{63}$

No randomized trials; keen group of enthusiasts $^{64}$

No randomized controlled trials except in the case of "concept" communities for substance misuse which have attendant coercion (one of the best controlled studies but not able to reach randomized allocation) ${ }^{65}$

Randomized trial in progress at present (Otto Kernberg's treatment for borderline personality disorder applied in formal research form $)^{66,67}$

Open studies supportive and randomized trial showed cost-effectiveness in patients with severe mental illness ${ }^{49-51,68}$

Contrasting results with very positive effects of haloperidol (7 mg/day) in first study but not replicated $^{69,70}$

Benefit of SSRIs in reducing self-harm and aggression-better evidence than most other treatments because of large trials, but some doubt over generalisability ${ }^{71-73}$

Some evidence of benefit from small randomized trials, but these were too small to yield clear evidence ${ }^{75,76}$
Detailed analysis suggests that CBT in brief form is only suited for non-borderline patients with limited self-harming behavior (further studies with longer treatment in progress)

More evidence awaited

Although the most established treatment in the United Kingdom for personality disorder, it is beginning to be supplanted by newer psychological therapies; forms adapted to day and home support seem to have best evidence of cost effectiveness

Well-established treatment awaiting evidence

New treatment focused on changing the environment to suit the person

No clear evidence of benefit despite widespread use in Cluster B personality disorder

Evidence only sufficient to regard both SSRIs and antipsychotics as "adjunctive" treatments in borderline personality disorder ${ }^{74}$

No clear guidelines about the use of these medications, but a strong drive to use atypical antipsychotic drugs in some personality disorders

*adapted from Tyrer $^{53}$ 
revealed that no article concerning personality disorder was to be found in a search of 48 articles in the 8 issues of PI (except for 3 articles on traits/character/temperaments), whereas the BJP and AJP had published similar amounts of articles on this subject. The BJP published 29 empirical research articles on personality disorder in 409 original research articles during this time (7.1\%). The AJP published 25 articles on personality disorders in 350 original research articles during this time $(7.1 \%)$. In addition, there was only 1 article concerning personality disorder originating from Korea published in the cited international journals during this period (except for 7 articles on traits/character/temperaments). This lack of data on personality disorder could be due to the lack of research sources and little funding available in Korea. These findings might also reflect the fact that many researchers view it as unimportant.

\section{Evidence for Treatment of Personality Disorder}

One of the difficulties with personality disorder has been its treatment-resistant feature and enduring problematic behavior. Most patients with personality disorder do not desire treatment and are therefore considered as treatment resisting (Type $\mathrm{R})$, whereas less than one in three patients with a personality disorder are treatment seeking (Type S). ${ }^{49}$ Usually, sufferers from personality disorder show a lack of awareness of the consequences of their behavior and frequently remain indifferent or blame others for the distress caused by their actions and interactions. Nidotherapy, in which the environment is changed, rather than the patient, may be suitable for the Type S majority. ${ }^{50-52}$

The reason that personality disorder is taken more seriously these days is that some effective treatments for the condition now exist. ${ }^{53}$ Although most patients with personality disorder do not desire treatment, a growing body of literature supports the view that patients who seek treatment for personality disorders show a steady improvement, both in the short and long term. ${ }^{36,39}$ Table 5 summarizes the treatments that have been tested adequately according to the tenets of evidence based medicine. No specific preferences are given in Table 3, but the evidence is summarized.

\section{Conclusions}

Personality disorders represent one of the major unresolved areas of psychiatry in Korea. Their important contribution to functional impairment has been largely ignored and their impact on the outcome of Axis I disorders has remained undetected in this country. Nowadays, we have better knowledge of their nature and course and are beginning to find ways to alter their core features. New treatments are now beginning to emerge which show evidence of efficacy and it is not unreasonable to hope that, in the near future, personality disorder will be better recognized and defined, able to be exposed without misunderstanding, and managed appropriately and well.

\section{- Acknowledgments}

Professor Peter Tyrer is the Chair of the WPA section on Personality Disorders. This work was supported by a Korea Research Foundation Grant (KRF-2009-013-E00019) and the Research and Scholarship Foundation in 2009 .

\section{REFERENCES}

1. Grant BF, Hasin DS, Stinson FS, Dawson DA, Chou SP, Ruan WJ, et al. Prevalence, correlates, and disability of personality disorders in the United States: results from the national epidemiologic survey on alcohol and related conditions. J Clin Psychiatry 2004;65:948-958.

2. Moran P, Jenkins R, Tylee A, Blizard R, Mann A. The prevalence of personality disorder among UK primary care attenders. Acta Psychiatr Scand 2000;102:52-57.

3. Tyrer P, Casey P, Gall J. Relationship between neurosis and personality disorder. Br J Psychiatry 1983;142:404-408.

4. Fazel S, Danesh J. Serious mental disorder in 23000 prisoners: a systematic review of 62 surveys. Lancet 2002;359:545-550.

5. Ranger M, Methuen C, Rutter D. Prevalence of personality disorder in the case road of an inner city assertive outreach team. Psychiatr Bull 2004;28:441-443.

6. American Psychiatric Association. Diagnostic and statistical manual of mental disorders (4th edition). Washington, DC: American Psychiatric Association; 1994.

7. World Health Organization. ICD 10 Classification of mental and behavioral disorders: Clinical descriptions and diagnostic guidelines. Geneva: World Health Organization; 1992.

8. American Psychiatric Association. Diagnostic and statistical manual of mental disorders (3rd edition). Washington, DC: American Psychiatric Association; 1980

9. Tyrer P, Seivewright N, Ferguson B, Tyrer J. The general neurotic syndrome: a coaxial diagnosis of anxiety, depression and personality disorder. Acta Psychiatr Scand 1992;85:201-206.

10. Crawford TN, Cohen P, First MB, Skodol AE, Johnson JG, Kasen S. Comorbid Axis I and Axis II disorders in early adolescence: outcomes 20 years later. Arch Gen Psychiatry 2008;65:641-648.

11. Newton-Howes G, Tyrer P, Johnson T. Personality disorder and the outcome of depression: meta-analysis of published studies. Br J Psychiatry 2006;188:13-20.

12. Beard JR, Heathcote K, Brooks R, Earnest A, Kelly B. Predictors of mental disorders and their outcome in a community based cohort. Soc Psychiatry Psychiatr Epidemiol 2007;42:623-630.

13. Newton-Howes G, Tyrer P, Weaver T. Social functioning of patients with personality disorder in secondary care. Psychiatr Serv 2008;59: 1033-1037.

14. Tyrer P, Mulder R, Crawford M, Newton-Howes G, Simonsen E, Ndetei D, et al. Personality disorder: a new global perspective. World Psychiatry 2010;9:56-60.

15. Tyrer P, Coombs N, Ibrahimi F, Mathilakath A, Bajaj P, Ranger M, et al. Critical developments in the assessment of personality disorder. $\mathrm{Br}$ J Psychiatry Suppl 2007;49:S51-S59.

16. Livesley WJ, Schroeder ML, Jackson DN, Jang KL. Categorical distinctions in the study of personality disorder: implications for classification. J Abnorm Psychol 1994;103:6-17.

17. Widiger TA, Simonsen E, Krueger R, Livesley WJ, Verheul R. Personality disorder research agenda for the DSM-V. J Pers Disord 2005; 19:315-338

18. Persly AS, Walton HJ. Dimensions of abnormal personality. Br J Psy- 
chiatry 1973;122:269-276.

19. Tyrer P, Alexander MS, Cicchetti D, Cohen MS, Remington M. Reliability of a schedule for rating personality disorders. Br J Psychiatry 1979;135:168-174.

20. Clark LA, Livesley WJ, Schroeder ML, Irish SL. Convergence of two systems for assessing specific traits of personality disorder. Psycholl Assess 1996;8:294-303.

21. Mulder RT, Joyce PR. Temperament and the structure of personality disorder symptoms. Psychol Med 1997;27:99-106.

22. Tyrer P, Alexander J. Classification of personality disorder. Br J Psychiatry 1979;135:163-167.

23. Eysenck HJ, Eysenck MW. Personality and individual differences: a natural science approach. New York: Plenum Press; 1985.

24. McCrae RR, Costa PT Jr. Validation of the five-factor model of personality across instruments and observers. J Pers Soc Psycholo 1987; 52:81-90.

25. Livesley WJ, Jang KL, Vernon PA. Phenotypic and genetic structure of traits delineating personality disorder. Arch Gen Psychiatry 1998; 55:941-948.

26. Cloninger CR, Przybeck TR, Svrakic DM. The tridimensional personality questionnaire: U.S. normative data. Psychol Rep 1991;69(3 Pt 1):1047-1057

27. Clark LA, Livesley WJ, Morey L. Personality disorder assessment: the challenge of construct validity. J Pers Disord 1997;11:205-231.

28. Mann AH, Jenkins R, Cutting JC, Cowen PJ. The development and use of standardized assessment of abnormal personality. Psychol Med 1981;11:839-847.

29. Pfohl B, Blum N, Zimmerman M. Structured interview for DSM-IV personality: SIDP-IV. Iowa City: University of Iowa, Department of psychiatry; 1995.

30. First MB, Spitzer RL, Gibbon M, Williams JBW. The Structured Clinical Interview for DSM-III-R Personality Disorders (SCID-II): Part 1: Description. J Pers Disord 1995;9:83-91.

31. Tyrer P, Alexander J, Ferguson B. Personality Assessment Schedule. In: Tyrer P, ed. Personality disorders: diagnosis, management and course (2nd ed). London: Arnold, London; 2000.

32. Moran P, Walsh E, Tyrer P, Burns T, Creed F, Fahy T. Impact of comorbid personality disorder on violence in psychosis: report from the UK700 trial. Br J Psychiatry 2003;182:129-134.

33. Schroeder ML, Wormsworth JA, Livesley WJ. Dimensions of personality disorder and their relationships to the big five dimensions of personality. Psychol Assess 1992;4:47-53.

34. Zanarini MC, Frankenburg FR, Hennen J, Silk KR. The longitudinal course of borderline psychopathology: 6-year prospective follow-up of the phenomenology of borderline personality disorder. Am J Psychiatry 2003;160:274-283.

35. Paris J. Implications of long-term outcome research for the management of patients with borderline personality disorder. Harv Rev Psychiatry 2002;10:315-323.

36. Seivewright H, Tyrer P, Johnson T. Change in personality status in neurotic disorders. Lancet 2002;359:2253-2254.

37. Shea MT, Stout R, Gunderson J, Morey LC, Grilo CM, McGlashan T, et al. Short-term diagnostic stability of schizotypal, borderline, avoidant, and obsessive-compulsive personality disorders. Am J Psychiatry 2002;159:2036-2041.

38. Shea MT, Yen S. Stability as a distinction between Axis I and Axis II disorders. J Pers Disord 2003;17:373-386.

39. Skodol AE, Oldham JM, Bender DS, Dyck IR, Stout RL, Morey LC, et al. Dimensional representations of DSM-IV personality disorders: relationships to functional impairment. Am J Psychiatry 2005;162: 1919-1925.

40. Grilo CM, Sanislow CA, Gunderson JG, Pagano ME, Yen S, Zanarini $\mathrm{MC}$, et al. Two-year stability and change of schizotypal, borderline, avoidant, and obsessive-compulsive personality disorders. J Consult Clin Psychol 2004;72:767-775.
41. Tyrer P, Morgan J, Cicchetti D. The Dependent Personality Questionnaire (DPQ): a screening instrument for dependent personality. Intl J Soc Psychiatry 2004;50:10-17.

42. Reich J, Nduaguba M, Yates W. Age and sex distribution of DSM-III personality cluster traits in a community population. Compr Psychiatry 1988;29:298-303.

43. Links PS, Heslegrave R, van Reekum R. Prospective follow-up study of borderline personality disorder: prognosis, prediction of outcome, and Axis II comorbidity. Can J Psychiatry 1998;43:265-270.

44. Seivewright H, Tyrer P, Johnson T. Persistent social dysfunction in anxious and depressed patients with personality disorder. Acta Psychiatr Scand 2004;109:104-109.

45. Paris J, Zweig-Frank H. A 27-year follow-up of patients with borderline personality disorder. Compr Psychiatry 2001;42:482-487.

46. Tyrer P, Johnson T. Establishing the severity of personality disorder. Am J Psychiatry 1996;153:1593-1597.

47. Oldham JM, Skodol AE, Kellman HD, Hyler SE, Rosnick L, Davies M. Diagnosis of DSM-III-R personality disorders by two structured interviews: patterns of comorbidity. Am J Psychiatry 1992;149:213220.

48. Dolan B, Evans C, Norton K. Multiple axis-II diagnoses of personality disorder. Br J Psychiatry 1995; 166:107-112.

49. Tyrer P, Mitchard S, Methuen C, Ranger M. Treatment rejecting and treatment seeking personality disorders: Type R and Type S. J Pers Disord 2003;17:263-268.

50. Tyrer P. Nidotherapy: a new approach to the treatment of personality disorder. Acta Psychiatr Scand 2002;105:469-471; discussion 471-472.

51. Tyrer P, Bajaj P. Nodotherapy: making the environment to the therapeutic work. Advances in Psychiatric Treatment 2005;11:232-238.

52. Tyrer P, Sensky T, Mitchard S. Principles of nidotherapy in the treatment of persistent mental and personality disorders. Psychother Psychosom 2003;72:350-356.

53. Tyrer P. Personality disorder. In: Murray RM, Kendler KS, McGuffin P, Wessely S, Castle DJ, editors. Essential Psychiatry. Cambridge: Cambridge University Press; 2008. p.135-146.

54. Bateman A, Fonagy P. Treatment of borderline personality disorder with psychoanalytically oriented partial hospitalization: an 18-month follow-up. Am J Psychiatry 2001;158:36-42.

55. Bateman A, Fonagy P. Health service utilization costs for borderline personality disorder patients treated with psychoanalytically oriented partial hospitalization versus general psychiatric care. Am J Psychiatry 2003;160:169-171.

56. Gerber AJ, Fonagy P, Bateman A, Higgitt A. Structural and symptomatic change in psychoanalysis and psychodynamic psychotherapy of young adults: a quantitative study of process and outcome. Journal of the American Psychoanalytic Association 2004;52:1235-1236.

57. Bateman A, Fonagy P. Effectiveness of partial hospitalization in the treatment of borderline personality disorder: a randomized controlled trial. Am J Psychiatry 1991;156:1563-1569

58. Linehan MM, Armstrong HE, Suarez A, Allmon D, Heard HL. Cognitive-behavioral treatment of chronically parasuicidal borderline patients. Arch Gen Psychiatry 1991;48:1060-1064.

59. Verheul R, Van Den Bosch LM, Koeter MW, De Ridder MA, Stijnen T, Van Den Brink W. Dialectical behaviour therapy for women with borderline personality disorder: 12-month, randomised clinical trial in The Netherlands. Br J Psychiatry 2003;182:135-140.

60. Evans K, Tyrer P, Catalan J, Schmidt U, Davidson K, Dent J, et al. Manual-assisted cognitive-behaviour therapy (MACT): a randomized controlled trial of a brief intervention with bibliotherapy in the treatment of recurrent deliberate self-harm. Psychol Med 1999;29:19-25.

61. Tyrer P, Thompson S, Schmidt U, Jones V, Knapp M, Davidson K, et al. Randomized controlled trial of brief cognitive behaviour therapy versus treatment as usual in recurrent deliberate self-harm: the POPMACT study. Psychol Med 2003;33:969-976.

62. Tyrer P, Tom B, Byford S, Schmidt U, Jones V, Davidson K, et al. Dif- 
ferential effects of manual assisted cognitive behavior therapy in the treatment of recurrent deliberate self-harm and personality disturbance: the POPMACT study. J Pers Disord 2004;18:102-116.

63. Guthrie E, Kapur N, Mackway-Jones K, Chew-Graham C, Moorey J, Mendel E, et al. Randomised controlled trial of brief psychological intervention after deliberate self poisoning. BMJ 2001;323:135-138.

64. Ryle A. The contribution of cognitive analytic therapy to the treatment of borderline personality disorder. J Pers Disord 2004;18:3-35.

65. Chiesa M, Fonagy P. Cassel personality disorder study. Methodology and treatment effects. Br J Psychiatry 2000;176:485-491.

66. Clarkin JF, Yeomans F, Kernberg OF. Psychotherapy for borderline personality. New York: Wiley; 1999.

67. Clarkin JF, Levy KN, Lenzenweger MF, Kernberg OF. The Personality Disorders Institute/Borderline Personality Disorder Research Foundation randomized control trial for borderline personality disorder: rationale, methods, and patient characteristics. J Pers Disord 2004; 18:52-72.

68. Ranger M, Tyrer P, Miloseska K, Fourie H, Khaleel I, North B, et al. Cost-effectiveness of nidotherapy for comorbid personality disorder and severe mental illness: randomized controlled trial. Epidemiol Psichiatr Soc 2009;18:128-136.

69. Cornelius JR, Soloff PH, Perel JM, Ulrich RF. Continuation pharmacotherapy of borderline personality disorder with haloperidol and phen- elzine. Am J Psychiatry 1993;150:1843-1848.

70. Soloff PH, George A, Nathan RS, Schulz PM, Ulrich RF, Perel JM. Progress in pharmacotherapy of borderline disorders disorders. A double-blind study of amitryptiline, haloperidol, and placebo. Arch Gen Psychiatry 1986;43:691-697.

71. Coccaro EF, Kavoussi RJ. Fluoxetine and impulsive aggressive behavior in personality-disordered subjects. Arch Gen Psychiatry 1997;54: 1081-1088.

72. Salzman C, Wolfson AN, Schatzberg A, Looper J, Henke R, Albanese $\mathrm{M}$, et al. Effect of fluoxetine on anger in symptomatic volunteers with borderline personality disorder. J Clin Psychopharmacol 1995;15:23-29.

73. Verkes RJ, Van der Mast RC, Hengeveld MW, Tuyl JP, Zwinderman AH, Van Kempen GM. Reduction by paroxetine of suicidal behavior in patients with repeated suicide attempts but not major depression. Am J Psychiatry 1998;155:543-547.

74. American Psychiatric Association Practice Guidelines. Practice guideline for the treatment of patients with borderline personality disorder. American Psychiatric Association. Am J Psychiatry 2001;158(10 Suppl):1-52.

75. Newton-Howes G, Tyrer P. Pharmacotherapy for personality disorders. Expert Opin Pharmacother 2003;4:1643-1649.

76. Tyrer P, Bateman A. Drug treatment for personality disorders. Advances in Psychiatric Treatment 2004;10:389-398. 